\title{
Efeito dos processos de laminação sobre as propriedades físicas e mecânicas de compósitos de resina de poliéster com fibras de vidro
}

\section{Effects of lamination processes on the physical and mechanical properties of fiberglass/polyester composites}

\author{
Ana Paula Peixoto Bittencourt ${ }^{1}$, Gabriel Benedet Dutra ${ }^{1}$, \\ Thiago Pontin Tancredi ${ }^{1}$
}

\footnotetext{
${ }^{1}$ Curso de Engenharia Naval, Centro de Joinville, Universidade Federal de Santa Catarina - UFSC, Santa Catarina, Brasil e-mail: ana.bittencourt@grad.ufsc.br; gabriel.d@ufsc.br; thiago.tancredi@ufsc.br
}

\begin{abstract}
RESUMO
As propriedades dos materiais compósitos utilizados pela indústria náutica são fortemente influenciadas pelo processo de fabricação. Neste escopo, este trabalho tem o objetivo de comparar rotas usuais de processamento de embarcações de recreio - laminação manual, laminação a vácuo e infusão - através de um estudo quantitativo das propriedades físicas e mecânicas de compósitos fibra de vidro/poliéster. A metodologia adotada consistiu na confecção de corpos de prova utilizando os diferentes processos, realização de ensaios de tração e absorção de água e cálculo de densidade superficial. A infusão foi o método que apresentou melhores resultados de resistência à tração e menores valores de densidade. Os corpos de provas de laminação manual absorveram mais água do que os demais. Como conclusão, verificou-se que a relação reforço/matriz alcançada pelo processo de infusão resultou em propriedades físicas e mecânicas melhores para os laminados do que as outras rotas investigadas. A laminação a vácuo mostrou-se uma alternativa intermediária em termos de propriedades físico-mecânicas.
\end{abstract}

Palavras-chave: fibra de vidro, laminação manual, laminação a vácuo, infusão, náutica.

\begin{abstract}
The properties of composite materials used in marine industry are strongly influenced by the manufacturing process. In this scope, this work aims to compare the usual production methods of yachting - hand lay-up, vacuum bagging, and infusion - through a quantitative study of the physical and mechanical properties of fiberglass/polyester composites. The methodology consisted in the manufacture of specimens using different processes, performance of tensile and water absorption testing, and surface density calculation. The infusion was the method that showed higher tensile strength results and lower density values. The hand lay-up specimens absorbed more water than others. In conclusion, it was noticed that the reinforcement/matrix rate achieved by infusion resulted in better physical and mechanical properties to the laminate than the other methods studied. The vacuum bagging showed up as an intermediate method in terms of physical and mechanical properties.
\end{abstract}

Keywords: fiberglass, hand lay-up, vacuum bagging, infusion, yachting.

\section{INTRODUÇÃO}

Embarcações que utilizam sustentação hidrodinâmica são chamadas embarcações de planeio. Neste caso, no equilíbrio vertical, além da força peso e do empuxo hidrostático, atua uma terceira força - denominada força de sustentação - que depende da velocidade da embarcação. Essa força faz com que a embarcação entre em regime de planeio dinâmico, variando o equilíbrio a cada instante. A dinâmica do equilíbrio resulta na constante imersão e emersão da proa dando origem a um esforço estrutural sobre o casco denominado slamming [1]. Esse, em geral, é consideravelmente superior ao esforço causado pela pressão hidrostática e pela pressão 
decorrente da interação do casco com as ondas. Desta forma, dois importantes requisitos das embarcações de alta velocidade são leveza e resistência - tornando-se importante que a embarcação seja leve para conseguir atingir o regime de planeio e ao mesmo tempo resistente o suficiente para suportar a pressão de slamming.

Materiais compósitos apresentam uma boa alternativa para esse tipo de projeto, pois combinam as propriedades leveza e resistência mecânica. Por essa razão, na indústria náutica, os compósitos denominados Plástico Reforçado de Fibra de Vidro (PRFV) são amplamente empregados [2]. Estes materiais aliam baixa densidade com excelentes propriedades mecânicas, tolerância à deterioração, resistência à corrosão e resistência à fadiga, e sabe-se que sua qualidade e custo são fortemente influenciados pelo processo de fabricação $[3,4,5]$.

Três métodos de obtenção de compósitos bastante utilizados no setor náutico são: laminação manual (LM), laminação a vácuo (LV) e infusão (I). A LM é considerada a técnica básica de fabricação de compósitos, enquanto que os métodos de LV e I são mais aprimorados, por utilizarem baixa pressão através da bomba de vácuo. Dentre os métodos sofisticados, em termos de materiais, a técnica de LV é a mais barata e a infusão gera um compósito com maior resistência mecânica e de melhor qualidade do que o método de laminação manual [6,7]. Além disso, ao levar em consideração os benefícios à saúde dos trabalhadores, a economia de recursos e a preservação ambiental, a infusão se destaca perante as outras técnicas [8].

Alguns grupos de pesquisa investigaram os impactos das diferentes formas de laminação nas propriedades mecânicas dos compósitos. NAJAFI et al. [9] avaliaram a influência do método de fabricação na resistência à compressão de compósitos-sanduíche (com núcleo inercial). Para o estudo, foram utilizadas fibras de vidro e de aramida como reforço, resina de poliéster como matriz e madeira balsa (Ochroma lagopus) como núcleo, e foram adotados como métodos a laminação manual e a infusão. Como conclusão, os autores constataram que o processo de fabricação claramente influencia a resistência à compressão do compósito. Em painéis sem a presença de núcleo inercial, FRANCO [10] realizou uma investigação da resistência à flexão, resistência ao impacto e teor de fibras em painéis de fibra de vidro e resina poliéster isoftálica, fabricadas por infusão e por laminação manual. Os resultados revelaram maior razão de fibra:resina nas placas produzidas via infusão, o que refletiu nas propriedades mecânicas. Por sua vez, YUHAZRI et al. [11] estudaram um método comparativo de laminação manual e de infusão com fibras naturais e poliéster, tendo a infusão apresentado resultados superiores de resistência à tração. Em geral, os estudos realizados revelam que existe uma influência significativa do método de fabricação nas propriedades finais dos compósitos, tendo sido reportados os melhores resultados para laminação por infusão.

Apesar de os estudos desenvolvidos no tema, a literatura ainda carece de uma comparação destas duas técnicas (LM e I) com um método alternativo de laminação - como a laminação a vácuo - pois as investigações publicadas são restritas às comparações diretas entre a laminação manual e por infusão. Desta forma, neste trabalho também será verificada uma forma similar e intermediária de laminação, apresentando um estudo comparativo dos processos de laminação manual, laminação a vácuo e infusão quanto às propriedades de tração, absorção de água e densidade superficial obtidas na fabricação de um compósito fibra de vidro/poliéster sem a presença de núcleo inercial. Com este estudo, será possível verificar se a laminação a vácuo pode ser um método transitório para estaleiros que visam migrar lentamente da laminação manual para a infusão.

\section{MATERIAIS E MÉTODOS}

\subsection{Confecção dos Corpos de Prova}

Inicialmente, foram laminadas três placas planas sobre o molde. Cada uma delas foi feita por um dos seguintes métodos: laminação manual, laminação a vácuo e infusão. Todas as placas foram reforçadas com fibra de vidro - tecido biaxial $\pm 45 \mathrm{de} 800 \mathrm{~g} / \mathrm{m}^{2}$ e manta de $450 \mathrm{~g} / \mathrm{m}^{2}$ - e compostas por resina de poliéster isoftálica com neo-pentil glicol (NPG), seguindo a configuração mostrada na Figura 1.

\begin{tabular}{|l|}
\hline manta \\
\hline tecido \\
\hline manta \\
\hline
\end{tabular}

Figura 1: Esquema representando as camadas do laminado. 
A laminação manual iniciou com a limpeza do molde e aplicação da cera desmoldante. Em seguida, depositou-se as camadas de resina e reforço segundo a Figura 1, com auxílio de pincel e compactador. Após 48 horas de cura foi realizada a desmoldagem da peça.

Na laminação a vácuo, as etapas iniciais, desde a colocação do desmoldante até impregnar a resina sobre os reforços, foram iguais àquelas da laminação manual. Entretanto, sobre o laminado foi colocado um filme de poliamida utilizado para proteger o laminado e facilitar a desmoldagem da placa. Na sequência, foi posicionado um plástico-bolha de polipropileno, com a finalidade de facilitar a passagem de ar em todas as regiões do laminado e absorver o excesso de resina. Por fim, cobriu-se com uma bolsa de vácuo composta por blenda polimérica de alta resistência, e selou-se todo o perímetro da bolsa com fita adesiva. A bomba de vácuo foi conectada à bolsa de vácuo e ligada até atingir valores de pressão na ordem de $500 \mathrm{mmHg}$. Após $30 \mathrm{~min}$, a bomba foi desligada e a peça permaneceu no molde até ocorrer a cura. Então, todas as camadas sobre o filme de poliamida, incluindo o mesmo, foram removidas e a peça foi desmoldada.

$\mathrm{Na}$ infusão, o processo de limpeza do molde e aplicação da cera foi idêntico aos anteriores. A seguir, foram posicionados os reforços secos, sem impregnação de resina, e sobre estes se colocou o filme de poliamida. Então, foram dispostas mangueiras espirais para fluxo do ar e uma mangueira de poliéster cristal para entrada da resina. Estes itens foram cobertos com a bolsa de vácuo e vedados na periferia com fita selante. A bomba de vácuo foi acionada até atingir valores de pressão na ordem de $500 \mathrm{mmHg}$. Então, a entrada de resina foi liberada por diferença de pressão e a bomba de vácuo ficou ligada por $30 \mathrm{~min}$. Após ocorrer a cura, a peça foi desmoldada. Todos os procedimentos de laminação foram realizados a temperatura de $25^{\circ} \mathrm{C}$ e as peças foram desmoldadas 48 horas depois do processamento.

Para obter os corpos de prova (CPs), as placas foram cortadas com o auxílio de uma serra tico-tico, nas dimensões recomendadas pelas normas ASTM D570 [12] e ASTM D3039 [13]. A fim de obter CPs com espessuras similares, foram descartados $5 \mathrm{~cm}$ de cada extremidade das placas. É importante notar que todos os CPs foram cortados na mesma orientação, em relação às fibras. Para o cálculo da densidade, foram usadas as dimensões recomendadas para o ensaio de absorção de água, ASTM D570 [12]. Para os ensaios de tração e cálculo de densidade, foram usados seis CPs de cada método; para o de absorção de água, três. A norma, o número e as dimensões dos CPs de cada ensaio estão mostrados na Tabela 1.

Tabela 1: Informações sobre os corpos de prova.

\begin{tabular}{c|c|c|c}
\hline Ensaio & Norma & $\begin{array}{c}\text { Número de CPs } \\
\text { por condição }\end{array}$ & $\begin{array}{c}\text { Dimensões de referência } \\
\text { (comprimento / largura) }\end{array}$ \\
\hline Tração & ASTM D3039 & 6 & $250 \mathrm{~mm} / 25 \mathrm{~mm}$ \\
\hline Absorção de Água & ASTM D570 & 3 & $76,2 \mathrm{~mm} / 25,4 \mathrm{~mm}$ \\
\hline Densidade Superficial & - & 6 & $76,2 \mathrm{~mm} / 25,4 \mathrm{~mm}$ \\
\hline
\end{tabular}

\subsection{Realização dos Ensaios}

\subsubsection{Cálculo da Densidade Superficial}

Dois fatores que mais influenciam no comportamento mecânico de peças compósitas são a razão entre o reforço e a matriz, e a porosidade das peças. Os vazios presentes na amostra podem interferir significativamente no desempenho da mesma, visto que são pontos concentradores de tensões e podem se tornar regiões de maior higoscopicidade. Uma das formas de se estimar a porosidade de uma peça é medir sua densidade.

Em laminados de pequena espessura (sem núcleo inercial), a metodologia utilizada para mensurar a densidade volumétrica pode resultar em erros significativos, visto que dependendo do método de laminação, a alta rugosidade da face do objeto pode influenciar no cálculo do volume a ser medido. Para evitar esses problemas, será utilizada a densidade superficial do laminado como medida comparativa entre os diferentes processos de fabricação. Por meio desse cálculo, pode-se determinar a massa de cada laminado por metro quadrado. Diferentemente dos itens posteriores, que serão baseados nas normas da ASTM, este é um cálculo simples fundamentado na equação 1, onde: $\rho_{\mathrm{A}}$ é a densidade superficial, $\mathrm{m}$ é a massa e A é a área da amostra.

$$
\rho_{A}=\frac{\mathrm{m}}{\mathrm{A}}
$$

Cada amostra teve comprimento e largura medidos com paquímetro em três pontos da respectiva orientação: dois nas extremidades e outro na região mediana. Então, calculou-se as médias e a área estimada da 
amostra por meio da multiplicação destas. A massa foi aferida por uma balança de sensibilidade $0,0001 \mathrm{~g}$.

Para este cálculo, foram utilizadas amostras similares às do ensaio de absorção de água. Suas dimensões de referência são apresentadas na Tabela 1; as amostras, na Figura 2.

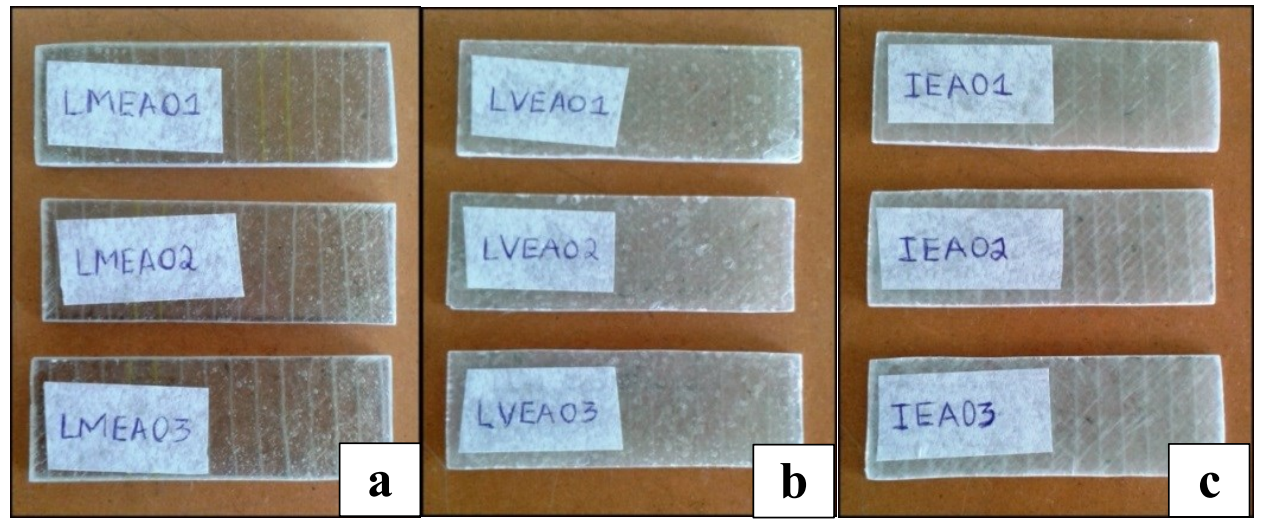

Figura 2: Amostras utilizadas para calcular a densidade superficial, de acordo com o tipo de fabricação (a) LM; (b) LV; (c) I.

\subsubsection{Ensaio de Tração}

As solicitações mecânicas que são aplicadas aos materiais durante serviço podem resultar em falhas como rompimentos de fibras, delaminação e propagação de trincas de maneira catastrófica. Para evitar situações indesejadas, é importante compreender o comportamento mecânico do material quando o mesmo for submetido a elevadas tensões. De forma a encontrar esta relação, foi realizado o ensaio de tração nas amostras confeccionadas sob diferentes métodos de laminação, conduzido com base na norma ASTM D3039 - norma para o ensaio padrão das propriedades de tração de materiais compósitos de matriz polimérica [13].

Antes de iniciar o teste, foram medidas a largura e a espessura de cada corpo de prova (CP) em três pontos - dois nas extremidades e um na região central - utilizando um paquímetro (sensibilidade: $0,05 \mathrm{~mm}$ ). Então, calculou-se a média da largura e da espessura. A velocidade do ensaio foi de $3 \mathrm{~mm} / \mathrm{min}$ até que ocorresse a ruptura do material.

No ensaio foi obtida a força máxima aplicada ao corpo de prova. Ao dividir a força obtida pela área calculada através da multiplicação das dimensões médias de espessura e de largura, obteve-se a tensão de ruptura. Na Figura 3 apresenta-se o corpo de prova LM01 posicionado na máquina universal de ensaios, durante a realização do teste de tração. Todas as amostras foram posicionadas no equipamento com o sentido das fibras do tecido em $\pm 45^{\circ}$ em relação ao eixo de aplicação de tração.

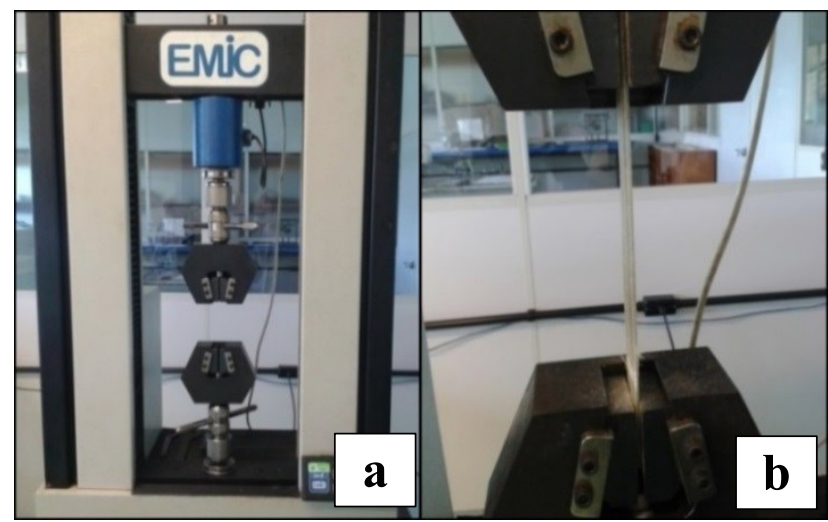

Figura 3: (a) Máquina universal de ensaios; (b) Corpo de prova tracionado.

\subsubsection{Ensaio de Absorção de Água}

Para o setor náutico, o efeito da água pode exercer um fator decisivo no desempenho de componentes estruturais de embarcações. Em chapas de materiais compósitos, a absorção de umidade pode trazer muitos danos estruturais à peça. Inicialmente, o processo interfere na plastificação da resina, seguida de um aumento de 
volume, visto que o espaçamento das moléculas principais do polímero tende a aumentar. Este fenômeno resulta no aumento das tensões internas no material, podendo gerar trincas e delaminação do compósito. Além disto, a fibra de vidro muitas vezes é coberta por agentes ligantes, chamados organosilanos, que têm afinidade com moléculas de água. Assim, as fibras podem funcionar como uma rede para percolação da água no compósito. Desta forma, é muito importante observar e acompanhar os efeitos da água em qualquer tipo de laminação. Em vista disso, conduziu-se o ensaio de absorção de água com base na norma ASTM D570 [12] - ensaio padrão para absorção de água de plásticos - com o objetivo de determinar a taxa relativa de absorção de água dos materiais quando imersos.

Inicialmente os CPs foram secados no forno a $50{ }^{\circ} \mathrm{C}$ por $24 \mathrm{~h}$ e resfriados num dessecador até a temperatura de $25^{\circ} \mathrm{C}$. A massa dos $\mathrm{CPs}$ foi medida em uma balança com sensibilidade de $0,0001 \mathrm{~g}$. A seguir, foram inteiramente submersos em água destilada. Após 24 h, os CPs foram removidos da água, enxutos com papel toalha, imediatamente pesados e recolocados na água. Esse procedimento foi repetido após $215,485,821 \mathrm{e}$ $1320 \mathrm{~h}$ decorridas da imersão inicial. Para diminuir erros gerados no processo de medição, foram feitas duas medições por condição - retirando e recolocando a amostra da balança - e sendo determinada a média das pesagens. Então, calculou-se a porcentagem de aumento na massa dos CPs de acordo com a equação 2:

$$
\text { Absorção de água }(\%)=\left(\frac{\text { massa após imersão - massa inicial }}{\text { massa inicial }}\right) \times 100
$$

\section{RESULTADOS}

\subsection{Cálculo da Densidade superficial}

A Figura 4 apresenta os valores de densidade superficial dos compósitos e os intervalos de confiança calculados pela distribuição t de Student com nível de confiança 95\%.

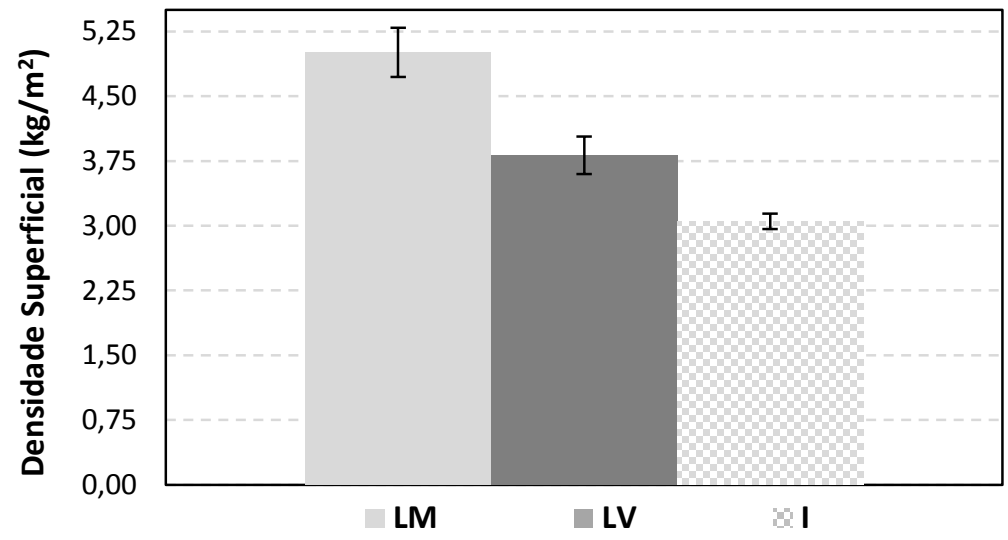

Figura 4: Gráfico comparativo da densidade superficial das placas de acordo com o tipo de fabricação.

Os resultados demonstram que, em média, a placa laminada por I $\left(3,05 \mathrm{~kg} / \mathrm{m}^{2}\right)$ tem valores de densidade superficial $20 \%$ menores do que a placa feita por $\operatorname{LV}\left(3,80 \mathrm{~kg} / \mathrm{m}^{2}\right)$ e $40 \%$ menores que a placa feita por LM $\left(4,98 \mathrm{~kg} / \mathrm{m}^{2}\right)$. Por fim, a placa feita por LV apresenta um valor de densidade superficial $24 \%$ menor do que a placa feita por LM. Os intervalos de confiança tiveram erros pequenos em relação à média: 5,6\% para LM, 5,6\% para LV e 2,9\% para I - evidenciando uniformidade nos resultados.

Como descrito anteriormente, o nível de porosidade da peça influencia diretamente na densidade da mesma. Quanto maior a quantidade de poros, menor a densidade obtida. Entretanto, outro fator determinante na densidade é a quantidade de resina retida no laminado. A resina em excesso no laminado aumenta a massa sem agregar reforço mecânico. Isto pode ser explicado com base na Tabela 2, que mostra a fração de fibras de cada placa e a massa da fibra, resina e laminado total. Antes de iniciar a laminação, foi aferida a massa dos reforços - tecido e mantas - de cada placa; e, posteriormente, verificou-se a massa das placas prontas. Então, calculou-se a massa da resina e a fração de fibras. 
Tabela 2: Massa da fibra, massa da resina, massa total e fração de fibras das placas de acordo com o tipo de fabricação.

\begin{tabular}{c|c|c|c|c}
\hline Método & Massa da fibra $\mathbf{( g )}$ & Massa da resina $\mathbf{( g )}$ & Massa total $\mathbf{( g )}$ & Fração de fibras (g/g) \\
\hline LM & 401 & 766 & 1167 & 0,34 \\
\hline LV & 347 & 526 & 873 & 0,40 \\
\hline I & 304 & 220 & 524 & 0,58 \\
\hline
\end{tabular}

Portanto, é possível afirmar que a placa de I apresenta a menor densidade superficial e a menor quantidade de resina retida do que o restante das peças (220 g). As amostras laminadas por LM são as mais densas e com maior quantidade de resina $(766 \mathrm{~g})$. Ao observar a massa da resina da Tabela 2 , fica evidente que a quantidade de resina em cada laminado foi claramente influenciada pelo processo adotado. Isto é explicado devido a utilização da bomba de vácuo na confecção das amostras, o que teve influência direta na fração de fibras do laminado, uma vez que a diferença de pressão faz com que o excesso de resina migre para fora da peça e fique retida no material absorvente.

\subsection{Ensaio de Tração}

Conforme pode ser observado na Figura 5, a posição de fratura das amostras variou significativamente entre os corpos de provas. Como as amostras são confeccionadas com duas camadas de direção de fibras, os esforços adquirem um comportamento anisotrópico ao longo do eixo do material. Este alinhamento de fibras em $\pm 45^{\circ}$ pode resultar em deformações angulares e no surgimento de tensões cisalhantes, influenciando no comportamento mecânico da peça. A fím de compreender este mecanismo de atuação de tensões em cada camada, estudos utilizando ferramentas de elementos finitos estão sendo feitos pelo grupo e serão posteriormente publicados.

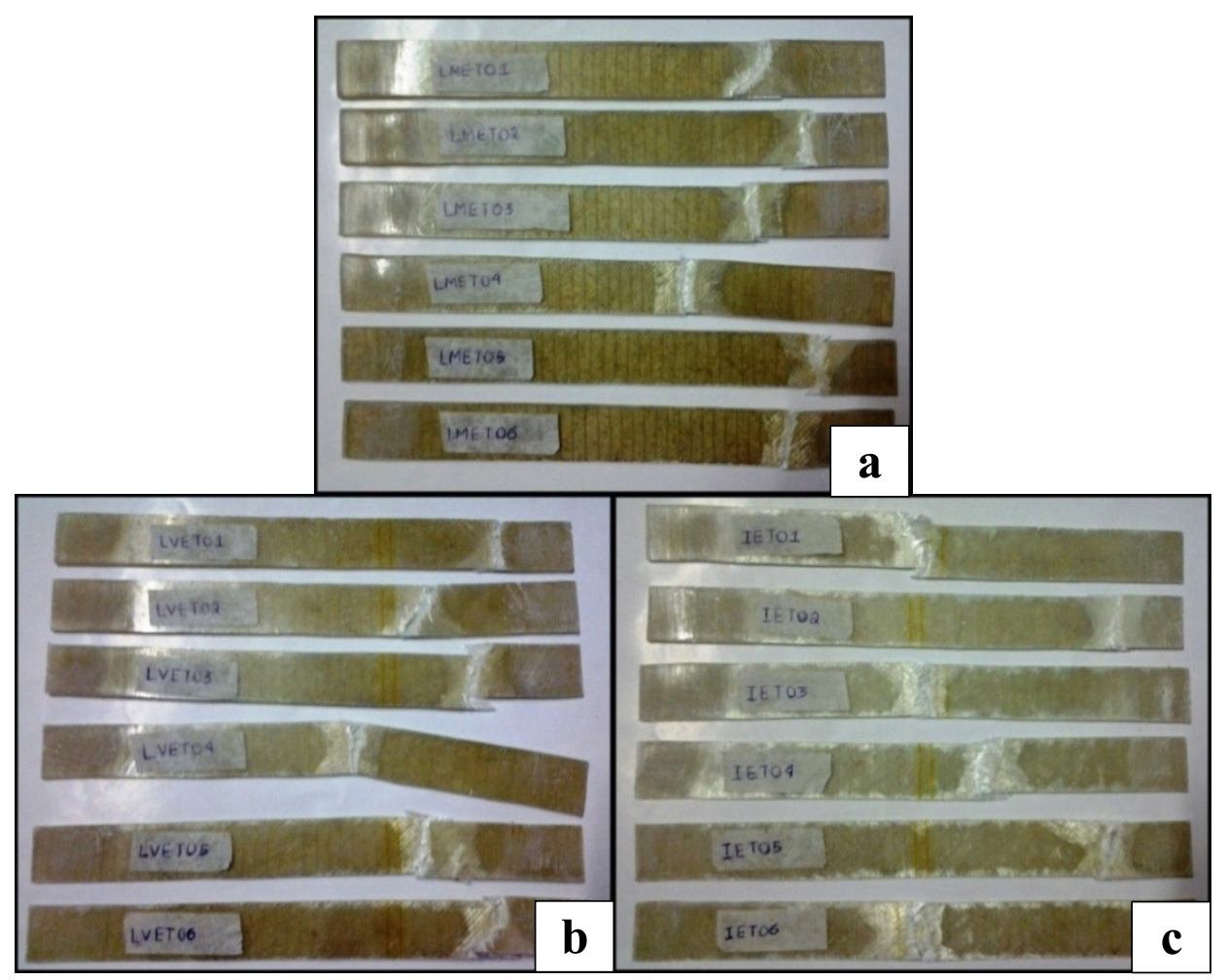

Figura 5: Amostras rompidas após ensaio de tração, de acordo com o tipo de fabricação (a) LM; (b) LV; (c) I.

Uma análise estatística foi realizada para avaliar os resultados experimentais (tensão de ruptura) obtidos nos diferentes corpos de prova ensaiados para cada um dos processos de fabricação estudados. Dessa análise, foram obtidos os valores de média, desvio padrão, intervalo de confiança e erro, utilizando a distribuição t de Student com nível de confiança 95\%. Estes valores estão apresentados na Figura 6. 


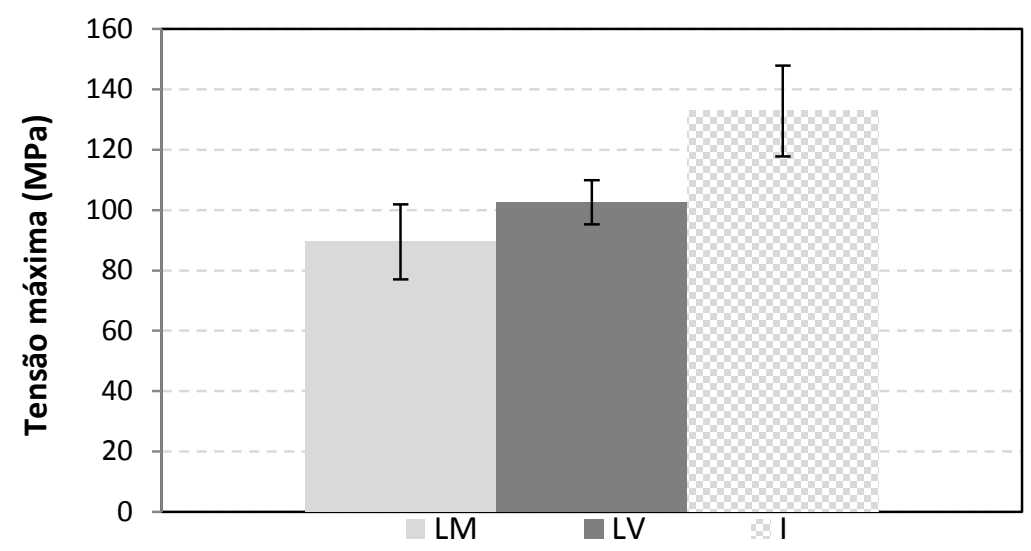

Figura 6: Resistência à tração das chapas de acordo com o tipo de fabricação.

Observando os resultados, nota-se que a resistência à tração média de $\operatorname{LV}(102,53 \mathrm{MPa})$ e I(132,76MPa) foram, respectivamente, $14,6 \%$ e 48,4\% superiores do que a de $\operatorname{LM}(89,46 \mathrm{MPa})$. Com relação ao método de LV, a chapa de I apresentou resistência média 29,5\% superior. Quanto aos intervalos de confiança, foi identificado um erro de 14\% para LM, 7\% para LV e 11\% para I. Logo, o método de infusão permitiu a obtenção de chapas com resistência à tração significativamente superior aos outros métodos; a laminação a vácuo apresentou resultados levemente superiores ao da laminação manual. Entretanto, esta diferença de LM e LV não pode ser identificada estatisticamente.

Isto pode ser explicado com base na Tabela 2, que demonstra que o método de I possui a maior fração de fibras, seguido de LV e LM. A fibra é o constituinte com as propriedades mecânicas mais significativas e, portanto, quanto maior o teor de fibra, mais adequado serão as propriedades do laminado - até um determinado teor de fibras [4]. Outro fator que justifica a obtenção de chapas com melhor comportamento físicomecânico relaciona-se com a utilização da bomba de vácuo, a qual reflete em uma menor quantidade de espaços vazios no laminado [14].

Além disto, alguns aspectos do ensaio precisam ser avaliados criteriosamente. A medida da tensão foi realizada através da força dividida pela área média do CP (verificada em três pontos distintos de cada $\mathrm{CP}$ ). Inerentemente ao processamento, há uma variação da área da seção transversal ao longo do corpo de prova, o que pode resultar em pontos de tensões superiores às registradas na Figura 6. Dessa forma, a máxima tensão suportada pelo corpo de prova antes da ruptura pode ser ainda mais elevada do que aquela que foi calculada.

Outro aspecto analisado foi a fixação dos corpos de prova na garra do equipamento. Devido à orientação das fibras no tecido biaxial, um pré-tensionamento das mesmas pode acontecer, em virtude da força exercida pela garra sobre a extremidade dos CPs. Uma constatação para este acontecimento pode ser verificada através do local da falha das amostras. Neste caso, serão avaliadas individualmente as amostras processadas pelo método de infusão. Na Figura 5c, as amostras I02 e I05 romperam próximas à posição da garra. A Tabela 3, mostra os valores de tensão máxima de cada amostra de infusão. De acordo com os valores obtidos, fica evidente a queda no valor de tensão para aquelas amostras que romperam próximas a garra (I02 - 119,87MPa e I05 114,21MPa), o que refletiu também em um alto intervalo de confiança das amostras I no gráfico apresentado na Figura 6.

Tabela 3: Dados do ensaio de tração respectivos aos CPs de Infusão.

\begin{tabular}{c|c|c|c}
\hline CPs & Área média $\left(\mathrm{mm}^{2}\right)$ & Força máxima (N) & Tensão máxima (MPa) \\
\hline 101 & 53,49 & 8174,00 & 152,81 \\
\hline 102 & 63,43 & 7603,00 & 119,87 \\
\hline 103 & 59,52 & 7853,70 & 131,95 \\
\hline 104 & 57,01 & 8174,00 & 143,38 \\
\hline 105 & 57,86 & 6607,40 & 114,21 \\
\hline 106 & 53,16 & 7143,50 & 134,37 \\
\hline
\end{tabular}

Recentemente, um artigo publicado por LAZARUS [15] na revista Professional Boatbuilders comenta 
tal influência. O artigo apresenta uma entrevista com Derek Novak, que é atualmente presidente e chefe de operações da divisão da ABS Pacific (American Bureau of Shipping), no qual é salientado que amostras laminadas com fibras orientadas podem concentrar tensões e interferir nos resultados de ensaios mecânicos.

Sendo assim, os valores absolutos medidos podem sofrer algumas alterações em virtude de área da seção transversal e/ou pré-tensionamento de fibras na região de contato com as garras. Entretanto, mesmo com tais observações a análise comparativa dos resultados é válida, pois todas amostras ensaiadas apresentam a mesma configuração de laminação e posicionamento das garras.

\subsection{Ensaio de Absorção de água}

Para o ensaio de absorção de água, a massa dos laminados foi monitorada em intervalos de tempo prédefinidos. Com estes valores foi montado o gráfico do aumento de massa (em \%) dos laminados em relação ao tempo, conforme a Figura 7. No gráfico, os valores indicam a média do ganho de massa para cada condição. As linhas apresentadas no gráfico foram adicionadas para facilitar a observação do leitor e a variação entre as medidas foi desprezível, não sendo possível visualizar a barra de erros no gráfíco da Figura 7.

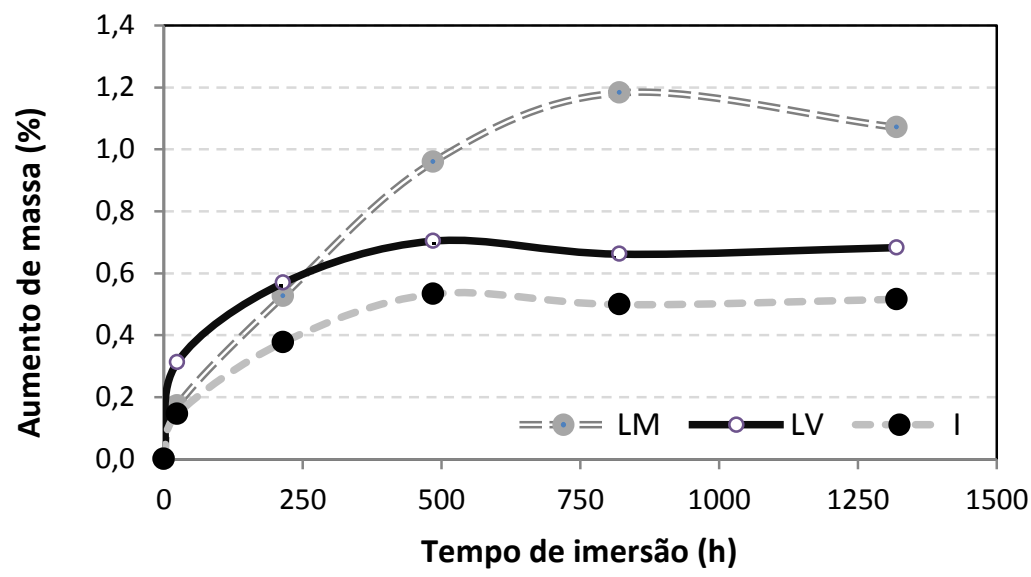

Figura 7: Absorção de água das chapas com a variação do tempo de acordo com o tipo de fabricação.

Nas primeiras $24 \mathrm{~h}$ as três chapas fabricadas apresentaram absorção de água acentuada. Neste período, LV foi quem mais absorveu água, tendo aumentado $0,31 \%$ de massa, enquanto que a LM e I absorveram quantidades parecidas, 0,17 e $0,15 \%$ respectivamente.

Após uma semana da primeira medição, LM havia absorvido 0,53\% enquanto LV tinha absorvido 0,57\% em massa. A partir deste momento, os CPs de LM passaram a absorver mais água do que os demais, estando em processo acentuado de absorção até a penúltima medição. Há duas hipóteses que podem colaborar com este fato: quantidade de resina em cada laminado e porosidade. Como observado na tabela 2, a quantidade de resina de cada laminado é distinta e consequentemente também a fração de fibras. Segundo VIEIRA et al. [16] "O aumento do teor de fibra de vidro no reforço diminui a absorção de água nos compósitos". Isto explicaria também a menor absorção dos CPs de I e a absorção intermediária dos CPs de LV. Além disto, a porosidade residual de cada processo pode ter influenciado o resultado, uma vez que as moléculas de água ficam retidas mais facilmente nos poros.

Por fim, torna-se possível inferir que existe uma tendência dos CPs de LV e I estabilizarem a absorção a partir da terceira semana de imersão, enquanto que a absorção dos CPs de LM ainda não havia estabilizado na última medição.

\section{DISCUSSÃO}

As investigações demonstraram que o método de infusão apresentou resultados superiores em termos de resistência à tração (vide Figura 6), de menor densidade superficial (vide Figura 4) e de menor absorção de água (vide Figura 7) do que as demais técnicas. Estes resultados estão condizentes com referências nacionais na área de compósitos para indústria náutica [5,17]. A infusão se caracteriza por uma ou mais entradas de resina de forma controlada e saídas de vácuo em lado oposto do painel. A diferença de pressão dentro do la- 
minado auxilia na remoção do ar e no preenchimento de maneira controlada das cavidades da peça pela resina ainda em estado líquido. Estas características do processo garantem um preenchimento mais uniforme e eficiente da resina no laminado, de forma a atingir uma maior relação reforço:resina, refletindo em uma melhor qualidade do laminado (densidade superficial, resistência à tração).

Além disto, a laminação a vácuo propiciou um leve aumento da resistência à tração, densidade superficial superior e menor absorção de água em relação à laminação manual. Esta técnica alternativa de laminação utilizando baixa pressão mostrou resultados quantitativos superiores aos da técnica de laminação manual. A utilização de uma bomba de vácuo após a laminação manual ajuda a retirar o excesso de resina do laminado, assim como poros aprisionados. A menor quantidade de resina e a menor quantidade de poros refletem em menor possibilidade de alocar moléculas de água dentro do laminado. Desta forma, a absorção de água, que é um fator importante para indústria náutica, é inferior àquela do laminado de forma manual (vide Figura 7).

Atualmente, muitos estaleiros utilizam a técnica de laminação manual devido à falta de investimento para rotas mais sofisticadas como a infusão. A transferência para uma técnica sofisticada pode ser vista como um passo muito distante para alguns estaleiros, de forma a inibir tais modificações de processo. Para estes casos, a laminação a vácuo pode ser um método alternativo ou até uma etapa de transição do processo de laminação manual para o processo de infusão.

Este trabalho complementa o que foi discutido e comentado na literatura em termos de formas de laminação, além de mensurar propriedades como absorção de água e densidade superficial. A Tabela 4 resume o que tem sido discutido e abordado na literatura atualmente.

Tabela 4: Trabalhos reportados na literatura em relação à comparação de métodos de laminação. .

\begin{tabular}{|c|c|c|c|c|}
\hline Autores & Materiais & $\begin{array}{c}\text { Propriedades } \\
\text { medidas }\end{array}$ & $\begin{array}{l}\text { Métodos de } \\
\text { laminação }\end{array}$ & $\begin{array}{l}\text { Resultados e } \\
\text { conclusões }\end{array}$ \\
\hline $\begin{array}{c}\text { NAJAFI et al. } \\
\text { [9] }\end{array}$ & $\begin{array}{l}\text { Fibra de Vidro } \\
+ \text { Poliéster }+ \\
\text { Madeira balsa }\end{array}$ & $\begin{array}{l}\text { Resistência à } \\
\text { compressão }\end{array}$ & LM e LI & $\begin{array}{c}\text { Compósitos sanduíche fabricados } \\
\text { por infusão propiciaram a obten- } \\
\text { ção de maiores valores de resis- } \\
\text { tência a compressão (28MPa) que } \\
\text { compósitos obtidos manualmente } \\
\text { (15MPa) }\end{array}$ \\
\hline FRANCO [10] & $\begin{array}{c}\text { Fibra de Vidro } \\
\text { + Poliéster }\end{array}$ & $\begin{array}{l}\text { Resistência à flexão } \\
\text { Resistência ao impac- } \\
\text { to } \\
\text { Teor de fibras }\end{array}$ & LM e LI & $\begin{array}{l}\text { Verificou-se que os laminados } \\
\text { fabricados por Infusão de Resina } \\
\text { apresentam maior resistência à } \\
\text { flexão, menor resistência ao im- } \\
\text { pacto e um superior conteúdo de } \\
\text { fibra. }\end{array}$ \\
\hline $\begin{array}{c}\text { YUHAZRI et } \\
a l .[11]\end{array}$ & $\begin{array}{l}\text { Fibra Natural } \\
+ \text { Poliéster }\end{array}$ & Resistência à tração & LM e LI & $\begin{array}{c}\text { O método de infusão mostrou } \\
\text { valores mais elevados de resis- } \\
\text { tência à tração do que os lamina- } \\
\text { dos manualmente }\end{array}$ \\
\hline Trabalho atual & $\begin{array}{c}\text { Fibra de Vidro } \\
+ \text { Poliéster }\end{array}$ & $\begin{array}{l}\text { Resistência à tração } \\
\text { Densidade superficial } \\
\text { Absorção de água }\end{array}$ & LM, LV e LI & $\begin{array}{l}\text { A relação reforço:matriz alcança- } \\
\text { da pelo processo de infusão resul- } \\
\text { tou em propriedades mecânicas } \\
\text { mais adequadas para os lamina- } \\
\text { dos e a laminação a vácuo mos- } \\
\text { trou-se como uma alternativa } \\
\text { intermediária em termos de pro- } \\
\text { priedades físico-mecânicas. }\end{array}$ \\
\hline
\end{tabular}

Também é importante salientar que tais modificações de processamento não refletem unicamente em propriedades físicas e mecânicas nos laminados. RICHE et al. [8] compararam em seu trabalho o método de 
laminação por infusão e manual, em relação a conceitos de produção limpa, eficiência produtiva e sustentabilidade nos negócios. Considerando a redução de material utilizado e a melhora das propriedades mecânicas, o custo de fabricação pode, eventualmente, compensar o maior investimento inicial com equipamentos permanentes exigidos pelo processo de laminação por Infusão.

\section{CONCLUSÕES}

A fração mássica de fibras identificada nos laminados feitos por cada método foi 0,58 para infusão, 0,40 para laminação a vácuo e 0,34 para laminação manual. Como a fibra é o constituinte com os maiores valores de tensão máxima, quanto maior for o seu teor, maiores valores serão obtidos pelo laminado.

Com relação ao ensaio de absorção de água, os CPs de laminação manual absorveram mais água do que os demais. Isto pode ser explicado pela maior quantidade de resina retida no laminado em conjunto com a porosidade residual resultante da não utilização de baixa pressão.

O cálculo de densidade superficial e da massa dos constituintes demonstrou que a o laminado feito por infusão apresenta menor quantidade de resina retida que as demais técnicas (valor de densidade superficial $20 \%$ menor que por laminação a vácuo). Com relação aos CPs de laminação manual, os confeccionados por laminação a vácuo apresentaram valores de densidade superficial $24 \%$ menores. Como os processos que utilizam bomba de vácuo retém a resina em excesso no material absorvente, é coerente que os CPs de laminação manual tenham apresentado densidade superficial mais elevada do que os demais.

Portanto, conclui-se que dos três métodos, a infusão é o que resulta num laminado com melhores propriedades físico-mecânicas. A laminação a vácuo produz laminados com propriedades intermediárias e a laminação manual gera laminados com propriedades inferiores.

Assim sendo, o método de laminação a vácuo pode ser uma alternativa para estaleiros que atualmente trabalham com laminação manual e buscam melhorias na qualidade do laminado final sem necessidade de elevado investimento para realizar uma infusão.

Como sugestão para trabalhos futuros, pode-se:

- Avaliar as diferentes metodologias adotadas em termos de tempo de fabricação, equipamentos e custos atrelados, por meio de uma análise econômica que considera o custo-benefício do processo de fabricação empregado;

- Testar diferentes tipos de resina e avaliar os efeitos da mesma em termos de absorção de água e propriedades mecânicas do compósito;

- Realizar uma análise de distribuição de tensões em cada camada e comparar os resultados experimentais com simulação de elementos finitos.

- Realizar a medida da porosidade residual de cada processo, de forma a se obter uma relação mais direta entre a quantidade de poros e as propriedades físicas e mecânicas do laminado.

\section{BIBLIOGRAFIA}

[1] DET NORSKE VERITAS. "Hull Monitoring Systems", In: Det Norske Veritas. Rules for classification of ships / high speed, light craft and naval surface craft, chapter 11, 2011.

[2] MAZUMDAR, S. K., Composites Manufacturing: Materials, Product, and Process Engineering, 1 ed., Florida, CRC Press LLC, 2002.

[3] SHENOI, R. A., WELLICOME, J. F., Composite materials in marine structures: fundamental aspects, 1 ed., New York, Cambridge University Press, 1993.

[4] MARINUCCI, G., Materiais Compósitos Poliméricos: Fundamentos e Tecnologia, 1 ed., São Paulo, Artliber, 2011.

[5] CARVAlHO, A., Fiberglass x Corrosão: Especificação, Instalação e Manutenção de Equipamentos de Fiberglass para Ambientes Agressivos, 1 ed., São Paulo, Asplar, 1992.

[6] Lombard, Z. AMT COMPOSITES, http:/www.amtcomposites.co.za/sites/default/files/media/howto/ AMTS-TP-15-2011-vacuum\%20infusion.pdf._Acessado em maio de 2015.

[7] AIREX BALTEK, http://www. 3accorematerials.com/downloads.html. Acessado em outubro de 2014. 
[8] RICHE, L., PABON, L., COHEN, M., "Processo de laminação por Infusão de Barcos de Lazer como Fonte de Sustentabilidade e Vantagem competitiva das Empresas do Setor Náutico Brasileiro", In: XXXIII Encontro da ANPAD, pp. 01-16, São Paulo, Set. 2009.

[9] NAJAFI, M., ESLAMI-FARSANI, R., KHALILI, S. M. R., "Comparison of compressive Properties Between Vacuum Infusion and Hand Lay-Up Method Toward Balsa Core Sandwich Composites", Journal Of Mechanical Research And Application, v. 4, n.2, pp. 33-40, Jan. 2013.

[10] FRANCO, R. A. V. S., Produção de componentes em materiais compósitos por infusão de resina, Dissertação de M.Sc., Universidade Técnica de Lisboa, Lisboa, 2008.

[11] YUHAZRI, Y. M., PHONGSAKORN, P. T., SIHOMBING, H., “A Comparison Process Between Vacuum Infusion and Hand Lay-Up Method Toward Kenaf/Polyster Composites”, International Journal of Basic \& Applied Sciences IJBAS-IJENS, v. 10, n. 3, pp.54-57, Jun. 2010.

[12] ASTM, American Society for Testing and Materials, D 570 - Standard Test Method for Water Absorption of Plastics", In: Annual Book of ASTM Standards, West Conshohocken, ASTM International, 1998.

[13] ASTM, American Society for Testing and Materials, D 3039 - Standard Test Method for Tensile Properties of Polymer Matrix Composite Materials”, In: Annual Book of ASTM Standards, West Conshohocken, ASTM International, 1995.

[14] WEST SYSTEM, http://www.westsystem.com/ss/assets/HowTo-Publications/Vacuum-BaggingTechniques.pdf. Acessado em setembro de 2015.

[15] LAZARUS, P., "Making and Testing Laminate Samples”, In: Professional Boatbuilder, WoodenBoat Publications, Inc, n.158, pp. 34-45, 2016.

[16] VIEIRA, C. A. B., MONDADORE, N. M. L., FREIRE, E., et al, "Interferência da lavagem de fibras sobre o desempenho do sizing nas propriedades mecânicas em compósitos híbridos vidro/sisal”, Revista Iberoamericana de Polímeros, v. 10, n. 4, pp. 222-234, Jul. 2009.

[17] NASSEH, J., Manual de construção de barcos, 4.ed., Rio de Janeiro, Barracuda Advanced Composites, 2011. 